\title{
Cell Cycle Regulation of Stem Cells by MicroRNAs
}

\author{
Michelle M. J. Mens ${ }^{1} \cdot$ Mohsen Ghanbari ${ }^{1,2}$
}

Published Online: 14 March 2018

(c) The Author(s) 2018

\begin{abstract}
MicroRNAs (miRNAs) are a class of small non-coding RNA molecules involved in the regulation of gene expression. They are involved in the fine-tuning of fundamental biological processes such as proliferation, differentiation, survival and apoptosis in many cell types. Emerging evidence suggests that miRNAs regulate critical pathways involved in stem cell function. Several miRNAs have been suggested to target transcripts that directly or indirectly coordinate the cell cycle progression of stem cells. Moreover, previous studies have shown that altered expression levels of miRNAs can contribute to pathological conditions, such as cancer, due to the loss of cell cycle regulation. However, the precise mechanism underlying miRNAmediated regulation of cell cycle in stem cells is still incompletely understood. In this review, we discuss current knowledge of miRNAs regulatory role in cell cycle progression of stem cells. We describe how specific miRNAs may control cell cycle associated molecules and checkpoints in embryonic, somatic and cancer stem cells. We further outline how these miRNAs could be regulated to influence cell cycle progression in stem cells as a potential clinical application.
\end{abstract}

Keywords MicroRNA $\cdot$ Cell cycle $\cdot$ Stem cells $\cdot$ ESC $\cdot$ Somatic stem cell $\cdot$ Cancer stem cell

\section{Introduction}

\section{Stem Cells and Cell Cycle Regulation}

Stem cells are characterized by their unlimited ability to self-renew and capability to differentiate into multiple cell lineages [1]. In this end, stem cells undergo an asymmetric cell division during which only one of the two daughter cells differentiates. This is a complex mechanism in which different transcription factors, epigenetic modifications and hormones are involved. There are two broad types of stem cells including embryonic stem cells (ESCs), which are solely present at the earliest stages of development, and somatic (or adult) stem cells, which appear during fetal development and remain throughout life. ESCs are pluripotent and therefore have the capacity to differentiate into all the possible cell types of the three germ layers. Somatic stem cells, however,

Mohsen Ghanbari

m.ghanbari@erasmusmc.nl

1 Department of Epidemiology, Erasmus University Medical Center, P.O. Box 2040, 3000 CA Rotterdam, The Netherlands

2 Department of Genetics, School of Medicine, Mashhad University of Medical Sciences, Mashhad, Iran are multipotent and can only differentiate into cell types of the specific tissue or organ from which they originate. It is also suggested that a certain type of stem-like cells is responsible for the initiation of cancer, so-called cancer stem cells (CSCs). It is thought that CSCs arise from either differentiated cancer cells or somatic stem cells [2].

In eukaryotes, the cell division cycle includes four discrete phases: Gap 1 (G1), Synthesis (S), Gap 2 (G2) and Mitosis (M). During the G1 phase, which is known as the first interphase, the cell synthesizes proteins that are needed for DNA replication and continuous growth. DNA replication takes place during the $\mathrm{S}$ phase and is followed by the $\mathrm{G} 2$ phase, which is known as the second interphase, where the DNA integrity is checked. At this point, the cell is growing and preparing for cell division. During the $\mathrm{M}$ phase, the cell divides into two daughter cells. After the mitotic phase, the daughter cells re-enter the G1 phase or go into the quiescent state. This is defined as a state of reversible cell cycle arrest and is known as the G0 phase [3]. The quiescent state is important for cellular homeostasis, meaning that it has the ability to either stop proliferating or to re-enter the cell cycle and self-renew when needed $[4,5]$.

The duration of the cell cycle and the transition from one phase to the next is highly variable between different 
cell types. While the cell cycle duration in murine somatic cells is relatively long $(>16 \mathrm{~h})$, the duration in murine ESCs (mESCs) is much faster $(8-10 \mathrm{~h})$. A reduced G1 phase and prolonged $\mathrm{S}$ phase in ESCs are the causes that make this difference. In addition, human ESCs (hESCs) spend only $3 \mathrm{~h}$ in the $\mathrm{G} 1$ phase, compared to human somatic cells that spend $10 \mathrm{~h}$ in this phase [6]. The difference in cell cycle duration between ESCs and somatic stem cells is remarkable, an explanation could be that somatic stem cells are predominantly in a quiescent state compared to the fast dividing ESCs. Previous studies have indicated that the G1 phase is the most variable phase and that its duration contributes to cell fate determination [7-9].

When a cell enters the G1 phase, a protein called cyclin $\mathrm{D}$ increases in response to mitogenic stimuli. Cyclin D proteins bind to enzymes called CDK4/6 and together they form heterodimers. These complexes subsequently phosphorylate proteins of the retinoblastoma $(R B)$ family. The $E 2 F$ family is a group of genes encoding for transcription factors $E 2 F-1$, $E 2 F-2$ and $E 2 F-3$, which are downstream targets of the $R B$ family. The central member of the $R B$ family, the $R B$ tumor suppressor protein $(\mathrm{pRb})$, is a negative regulator of the $E 2 F$ genes. When $\mathrm{pRb}$ is hypophosphorylated, it inactivates $E 2 F$ transcription factors, which results in the inhibition of transition from $\mathrm{G} 1$ to $\mathrm{S}$ phase. Hyperphosphorylation of $\mathrm{pRb}$ leads to dissociation of $E 2 F$ from the $E 2 \mathrm{~F} / \mathrm{pRb}$ complex and contributes to the G1/S transition. Recent findings show the importance of the $\mathrm{E} 2 \mathrm{~F} / \mathrm{pRb}$ activity in relation to ESCs selfrenewal and differentiation [10-12].

Cyclin dependent kinase proteins (CDK) tightly regulate the progression of the cell cycle. A CDK binds to its regulatory cyclin protein partner to control the different cell cycle phases. Progression through $\mathrm{S}$ phase is regulated by the cyclin E-CDK2 complex, while the $\mathrm{G} 2 / \mathrm{M}$ transition is under control of cyclin B-CDK1 complex. Cyclin dependent kinase inhibitor (CDKI) proteins including p21/Cip1, p27/Kip1 and p57/Kip2, block the activity of cyclin E-CDK2 and cyclin A-CDK1 [13]. Furthermore, proteins of the INK4 family, including p16/INK4A, p15/INK4B, p18/INK4C and p19/INK4D inhibit the cyclin D-CDK4/6 activity. These mechanisms can lead to cell cycle arrest and are of major importance to regulate tissue homeostasis and prevent tumorigenesis. The p53-p21 signaling pathway is also involved in the transition of $\mathrm{G} 1$ to $\mathrm{S}$ phase and $\mathrm{G} 2$ to $\mathrm{M}$ phase. It is well established that loss of p53 is the main reason for genomic instability as the p53-null cells have disrupted the G1/S checkpoint [14-17]. In addition, the expression levels of p53 and p21 in ESCs are important for the maintenance of pluripotency [18].

\section{Biogenesis of MicroRNAs}

Epigenetic features, such as the activity of microRNAs (miRNAs), modulate the expression of cell cycle-associated genes [19-23]. MiRNAs are a conserved class of endogenously expressed small non-coding RNAs (spanning 20-24 nucleotides), that have been widely implicated in fine-tuning various biological processes. Since the discovery of the first miRNA in 1993 [24], the knowledge on miRNAs has been rapidly increased. MiRNAs are ubiquitously expressed in plants, animals and viruses, indicating the evolutionary importance of these small molecules. According to the miRBase database (v.21), 1881 miRNAs have been identified with confidence in human [25]. These miRNAs are suggested to regulate the expression of more than $60 \%$ of all protein-coding genes. Previous research has investigated the functional role of miRNAs in diverse mechanisms including cell proliferation, apoptosis, and differentiation. Additionally, alteration in the expression of miRNAs contribute to human diseases such as cancer and cardiovascular disease [26-33].

MiRNA maturation is a complex biological process that is subjected to tight molecular regulation. In the nucleus, miRNAs are initially transcribed as 800-3000nt long primary transcripts (pri-miRNA). These pri-miRNAs are subsequently cleaved by Drosha, RNaseII, endonuclease III, and Pasha/DGCR8 proteins to generate $~ 70$ nt hairpin precursor miRNAs (pre-miRNAs). Following this initial process, pre-miRNAs are transported to the cytoplasm by Exportin 5. Subsequently, the hairpin precursor is cleaved in a 22nt double-stranded miRNA by the ribonuclease III enzyme called Dicer together with TRBP/ PACT proteins. The guide strand ( $5^{\prime}$ end) then associates with members of the Argonaute family and is been incorporated into the RNA-induced silencing complex (RISC). The miRRISC complex facilitates base-pairing interaction between miRNA and the $3^{\prime}$ untranslated region ( $\left.3^{\prime} \mathrm{UTR}\right)$ of target mRNA. The core of a mature miRNA, called the 'seed' region, includes nucleotides $2-7 / 8$ from the 5 ' end of the miRNA and plays a critical role in target recognition and interaction. Binding of the miRNA seed region to its complementary site in the target mRNA leads to translational repression or degradation of the target transcript.

The first studies investigating miRNA function in cell cycle regulation were published two decades ago, where two independent studies revealed that miRNAs lin- 4 and let-7 induce cell cycle arrest in the nematode, $C$. elegans $[24,34]$. Since then, several studies have demonstrated the importance of miRNAs in cell cycle regulation in different cell types including stem cells $[21,35,36]$. The role of miRNAs in stem cell proliferation was initially observed in knockout mice lacking Dicer and Dgcr8, which are key 
components of the miRNA biogenesis [37]. Dicer knockout mice were embryonic lethal and ESCs from Dicerdeficient mice exhibited defects in cell cycle progression [38]. Similarly, ESCs derived from Dgcr8-deficient mice exhibited delay in the cell cycle progression due to downregulation of genes involved in regulation of self-renewal [37]. These initial studies indicated that miRNAs are crucial for cell cycle regulation of stem cells. Then, other studies demonstrated that miRNAs are involved in the cell cycle progression of stem cells by direct or indirect targeting of different cell cycle-associated genes (e.g. Cyclins, CDKs and CDKIs). Understanding the tightly regulated networks of cell cycle in which miRNAs are interacting, will enhance our knowledge in the development of both healthy and disease states of the human body. In the following, we will discuss the recent advances on the functions of miRNAs in cell cycle regulation of stem cells. In addition, a promising therapeutic potential of miRNAs in controlling somatic and cancer stem cells self-renewal and proliferation will be discussed.

\section{MiRNAs and Cell Cycle Regulation of Stem Cells}

\section{Embryonic Stem Cells (ESCs)}

The duration of the cell cycle is variable between different types of stem cells. ESCs have a shorter cell cycle compared to somatic stem cells, which is due to a significantly abbreviated G1 phase and a prolonged S phase [39-41]. Previous studies have explored the phosphorylation status of $\mathrm{pRb}$ as a regulator for the length of G1 phase. Since mESCs lack cyclin D-CDK4 as well as cyclin E-CDK2, pRb will not be phosphorylated and thereby not stimulating the cyclin E-CDK2 activity [42]. Therefore, the time spent in G1 phase compared to $\mathrm{S}$ phase may be a key feature of the pluripotency fate [12]. Moreover, DNA damage response pathways, which are activated in the G1 phase, are reduced or absent in both hESCs and mESCs [43]. Several negative regulators of cell cycle progression, including p53, p16/INK4A, p19/ ARF and p21/Cip1, are expressed at low levels in ESCs, while DNA repair and replication regulators are expressed at high levels [6, 43].

Previous studies have shown the distinct expression pattern of miRNAs in ESCs. These studies demonstrate that ESCs express a set of miRNAs, of which a few are abundantly expressed at 60,000 or more copies per cell. The most abundantly expressed miRNAs in ESCs are miR-290-295, miR-302, miR-17-92, miR-106b-25 and miR-106a-363 clusters, which provide approximately $70 \%$ of the total miRNA molecules in ESCs [20, 44-46]. These miRNAs are expressed in homologous clusters, so-called polycistronic loci, which contribute to the same cis-regulatory elements [47]. The miR-290-295 cluster and miR-302 share a highly conserved seed-sequence 'AAGUGCU', while miR-17-92, miR-106b-25 and miR-106a-363 clusters share the seedsequence 'AAAGUGC' [20]. These miRNAs are called the regulators of the embryonic stem cell cycle (ESCC), because of the ability in rescuing cell cycle progression in Dgcr8 knockout ESCs [20, 44, 48-50]. A schematic overview of the functionality of ESCC miRNAs is illustrated in Fig. 1. In general, ESCC miRNAs facilitate the G1/S transition mainly through suppressing the expression of RB proteins [44]. In addition, these miRNAs have been demonstrated to directly regulate the expression of p21/Cip1 and cyclin E-CDK2 regulatory molecules in mESCs, including $R B, R B L 1, R B L 2$, and LATS2 [21, 48-50].

The miR-290 cluster, consisting of miR-291a-3p, miR291b-3p, miR-294, and miR-295, is upregulated in undifferentiated ESCs, but is rapidly downregulated during differentiation $[21,50,52]$. It has been shown that members of this miRNA cluster promote the G1/S transition. Cells can relatively quick enter the $S$ phase, because members of the miR290-295 cluster directly target cyclin D-CDK4/6 and indirectly downregulate the cyclin E-CDK2 complex (Fig. 1). MiR-290-295 downregulates diverse inhibitors of the cell cycle, including $R B, R B L 1, R B L 2, \mathrm{p} 21$ and $L A T S 2$, which change the distribution of ESC in each cell cycle phase [47]. Furthermore, the miR-290-295 cluster enhances the somatic reprogramming by increasing the expression of pluripotent transcription factors OCT4, SOX2, KLF4, LIN28, MYC and NANOG [47, 53]. Also, miR-290-295 is shown to be directly involved to suppress apoptosis by targeting Caspase 2 [54]. This leads to a reduced percentage of ESCs in G1 phase and an increased fraction of cells in S or G2/M phases. Due to the enhanced proliferation, the metabolism of ESCs rather rely on glycolysis than aerobic respiration. This metabolism is similar to the Warburg effect that is known in cancer cells $[44,47,48]$. Therefore, glycolysis-associated genes, such as MYC, LIN28 and HIF 1, have been promoted by the miR-290-295 cluster [44, 47]. Moreover, members of this miRNA cluster could affect epigenetic pathways including DNA methylation, histone acetylation and activation of Polycomb proteins, which inactivates genes involved in differentiation $[55,56]$.

The miR-17-92 cluster consists of miR-17, miR-18a, miR-19a, miR-19b, miR-20a and miR-92a. This miRNA cluster is crucial in early mammalian development by supporting cellular reprogramming and tumorigenesis [44]. In particular, miR-17-92 is a regulator of the $M Y C$ oncogene $[51,57] . M Y C$ inhibits the expression of chromatin regulatory genes including $S I N 3 B, H B P 1$, and $B T G 1$, via miR17-92. Through epigenetic mechanisms including reduced recruitment of histone deacetylase $(H A D C)$ via $H B P 1$, miR17-92 controls the chromatin stage of cell cycle related genes 


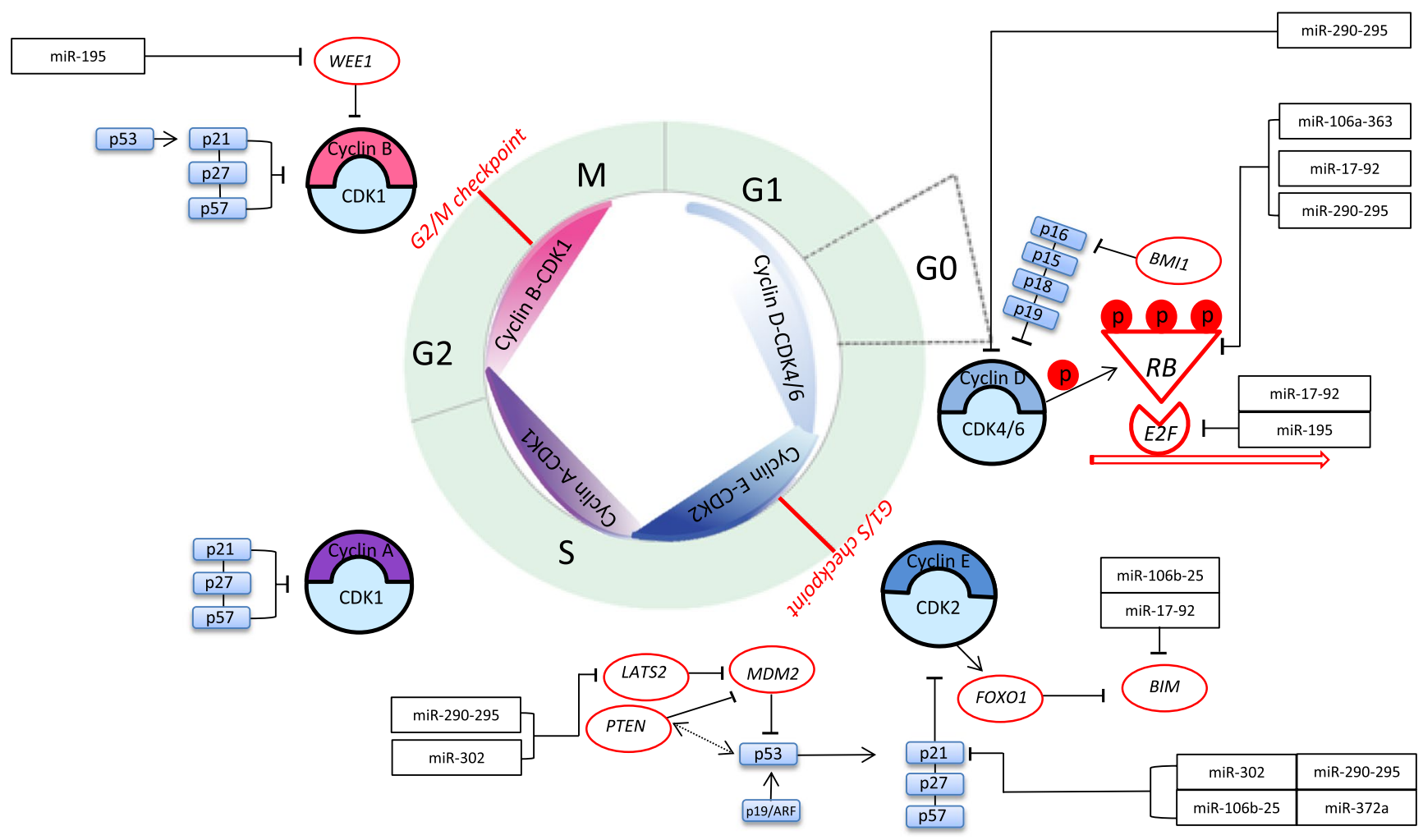

Fig. 1 An overview of cell cycle regulation in ESCs by miRNAs. The figure illustrates the cell cycle progression in embryonic stem cells (ESCs). As shown, multiple key regulatory elements including cyclins, CDKs and CDK inhibitors are forming a network that progress cells through the four different phases of cell cycle. Several miRNA clusters and single miRNAs are involved in the regulation of cell cycle in ESCs by directly or indirectly targeting the cell cycle-associated components (e.g. RB, p53, p21, LATS2, PTEN, cyclin D, cyclin E). Among them, miR-17-92, miR-290-295, miR-302, miR-106b-25 and miR-106a-363 are abundantly expressed in ESCs. Inhibition of $E 2 F$ by miR-92 and miR-195 decreases transcription of

(Fig. 1) [51]. MYC through miR-17-92, contributes to the euchromatin formation of specific gene expression involved in DNA replication and repair mechanisms that goes along with a shift in the percentage of cells in a proliferating state [51]. Likewise, miR-106b, which shares a high sequence homology with miR-17 and miR-20a, is shown to promote G1/S transition by directly targeting $\mathrm{p} 21$, which results in a higher portion of cells in S phase compared to G1 phase [58].

The miR-302-367 cluster, consisting of miR-302a, b, c, $\mathrm{d}$, and miR-367, has also been shown to play a crucial role in the proliferation of ESCs. Members of the miR-302-367 cluster are highly expressed in early stages of embryonic development [59]. This miRNA cluster targets genes that are involved in epigenetic mechanisms. For example, the miRNA cluster downregulates lysine demethylases and CpG binding proteins MECP1-p66 and MECP2 [59]. This facilitates the transcription of pluripotent genes and thereby multiple transcription factors and proteins (e.g. $E 2 F-1, E 2 F-2, E 2 F$ 3, $C D K 2, C D C 25 A$ ), resulting in a reduction of G1 phase duration. Furthermore, the expression of main G1/S and G2/M checkpoint regulator p53 is decreased via indirect targeting by miR-290-295 and miR-302 in ESCs. This facilitates the G1/S transition. Moreover, p21 expression is reduced via miR-290-295, miR-372a, miR-302 and miR-106b-25 in a direct manner. This inhibits cyclin E-CDK2 activity, and therefore facilitates the G1/S transition. Additionally, miR106b-25 and miR-17-92 can target pro-apoptotic gene BIM, resulting in a reduction of cells entering apoptosis [51]

contributes to the sustenance of pluripotency in mammalian ESCs [59]. Furthermore, it has been demonstrated that the promoter of miR-302-367 is activated when bound by OCT4, SOX2, which are core transcription factors directly involved in the maintenance of ESCs $[59,60]$. It has been also shown that this cluster promotes pluripotency in ESCs by targeting the SMAD signaling pathway and the PI3K/PKB signaling molecules. MiR-302 inhibits the expression of transforming growth factor beta-receptor 2 (TGFBR2) and RAS homolog gene family member $\mathrm{C}(R H O C)$, which leads to a reduction of epithelial-mesenchymal transition [59, 61, 62]. In addition, the miR-302 cluster has suggested to negatively regulates p21 and LATS2 activity in both hESCs and mESCs [63, 64]. These molecular mechanisms enlighten the important role of the miR-302-367 cluster with respect to pluripotency and cell cycle modulations.

Another well-known miRNA family involved in the regulation of cell cycle progression is the let-7 family, which 
consist of let-7a-1, a-2, a-3, b, c, d, e, f-1, f-2, g, i and miR98. Members of this miRNA family affect the G1/S transition of ESCs differently than the above-described ESCC miRNAs. While most of the ESCC miRNAs are related to promote self-renewal, the let-7 miRNAs suppress selfrenewal $[35,52]$. The mechanism underlying this antagonistic effect remains unclear. However, it has been suggested that the ESCC miRNAs positively regulate the expression of $L I N 28$, which through a negative feedback loop suppress the let-7 maturation $[65,66]$.

Two other miRNAs known to affect the regulation of ESCs are miR-195 and miR-372a. Both miRNAs are highly enriched in hESCs compared to differentiated cells and their function also relies on maintaining the proliferative capacity of hESCs [67]. For example, ectopic expression of miR-195 results in reduced expression of the G2/M cell cycle checkpoint kinase WEE1 and an enhancement of BrdU incorporation $[67,68]$. Ectopic expression of miR-372 has also shown to reduce the p21 expression levels in Dicerknockdown hESCs [67].

Human ESCs have the therapeutic potential to treat a myriad of disorders by cell replacement. In theory, ESCs could be used in regenerative medicine, drugs discovery and disease modeling. However, the usage of ESCs as clinical application is limited because of high tumorigenicity and ethical restrictions. A miRNA-based therapy that use induced pluripotent stem cells (iPSC) might overcome these limitations. In this regard, ectopic expression of ESCC miRNAs may contribute to expansion of stem cells for regenerative medicine purposes [12, 20, 44].

\section{Somatic Stem Cells}

An extensive body of research has revealed the role of miRNAs in the cell cycle regulation of somatic stem cells [45, $69,70]$. In particular, studies with tissue specific Dicerknockout or Dgcr8-deficient mice have demonstrated that miRNAs are essential regulators of proliferation, survival and differentiation in somatic stem cells [71]. In the following paragraphs, the role of miRNAs in the cell cycle regulation of hematopoietic and mesenchymal stem cells will be discussed. The associations of miRNAs with other somatic stem cells are summarized in Table 1.

Hematopoietic stem cell (HSC) development has been characterized by several mechanisms that lead to generating multiple cell lineages. Adult HSCs are predominantly quiescent (in the G0 phase) compared to fetal HSCs [4]. Well established is the self-renewal function of the LIN28 gene, which is highly expressed in fetal HSCs compared to adult HSCs (Fig. 2b) [95, 96]. This is a form-feedback loop which includes the downregulation of let-7 through LIN28, and subsequently downregulation of HMGA2. Given that $H M G A 2$ enhances the self-renewal capacity, the
Table 1 miRNAs associated with cell cycle regulation in somatic stem cells

\begin{tabular}{|c|c|c|c|}
\hline Stem cell & miRNA ID & Potential target gene(s) & Reference \\
\hline \multirow[t]{5}{*}{ Epidermal } & miR-205 & PI3K-AKT & {$[72]$} \\
\hline & miR-203 & SNAI2, p63, SNAP2 & [73] \\
\hline & $\operatorname{miR}-34$ & p63 & [74] \\
\hline & miR-184 & NOTCH, p63, FIH1 & [75] \\
\hline & miR-214 & $W N T / \beta$-catenin & [76] \\
\hline \multirow[t]{8}{*}{ Neural } & miR-9 & $T L X, B A F 53 A$ & [77] \\
\hline & miR-137 & $T L X$ & [78] \\
\hline & miR-184 & $M B D 1$ & [79] \\
\hline & miR-195 & $M B D 1$ & {$[80]$} \\
\hline & miR-124 & $S O X-2, P T B P 1, S C P 1$ & [81-83] \\
\hline & miR-302 & p53, OCT4, SOX2, NANOG & [84] \\
\hline & $\operatorname{miR}-148 b$ & $W N T / \beta$-catenin & {$[85]$} \\
\hline & miR-138 & TRIP6 & {$[86]$} \\
\hline \multirow[t]{8}{*}{ Muscle } & $\operatorname{miR}-27$ & $P A X 3$ & [87] \\
\hline & miR-322 & $C D C 25 A$ & {$[88]$} \\
\hline & miR-206 & $H D A C 4, P A X 7$ & {$[89,90]$} \\
\hline & miR-1 & $H D A C 4, P A X 7$ & [90] \\
\hline & miR-133 & $S R F, M A L A T 1$ & [91] \\
\hline & miR-221 & $P I 3 K-A K T$ & [92] \\
\hline & miR-143 & $I G F B P 5, E R K 1 / 2$ & [93] \\
\hline & $\operatorname{miR}-486$ & $P A X 7$ & [94] \\
\hline
\end{tabular}

LIN28-HMGA2 pathway is crucial in stem cell development [97]. Most of the previous research has focused on determining the expression of miRNAs in hematopoietic stem and progenitor cells during lineage differentiation [98]. Several studies have also reported differential miRNA expressions between HSCs, hematopoietic progenitor cells and both myeloid and lymphoid linages (e.g. T cell, B cell, Granulocyte, Monocyte, Erythrocyte), demonstrating that miRNAs are involved in the differentiation of specific hematopoietic lineages [95, 99-101]. Although the conventional model suggests that hematopoietic lineages are derived from a common HSC, more recent research revealed that a rather large number of progenitor cells are the main drivers behind steady-state hematopoiesis and clonal diversity [102]. In this regards, short-term HSCs could support the heterogeneous range of progeny [102]. Taken the functional role of miRNAs into consideration, both progenitor cells and diverse miRNAs may be equally important for clonal expansion and hematopoiesis.

For example, miRNAs are differentially expressed between long term hematopoietic stem cells (LT-HSCs) and short term HSCs, which are defined by a combination of cell surface markers such as c-Kit ${ }^{+} / \mathrm{Sca}^{-} 1^{+} / \mathrm{Lin}^{-}(\mathrm{KSL})$. Based on the expression levels of cell surface markers including CD34, Flk-2, CD150, CD48, CD224, c-Kit, Sca-1, and Lin, the heterogeneous population of HSCs differ in proliferation 
a
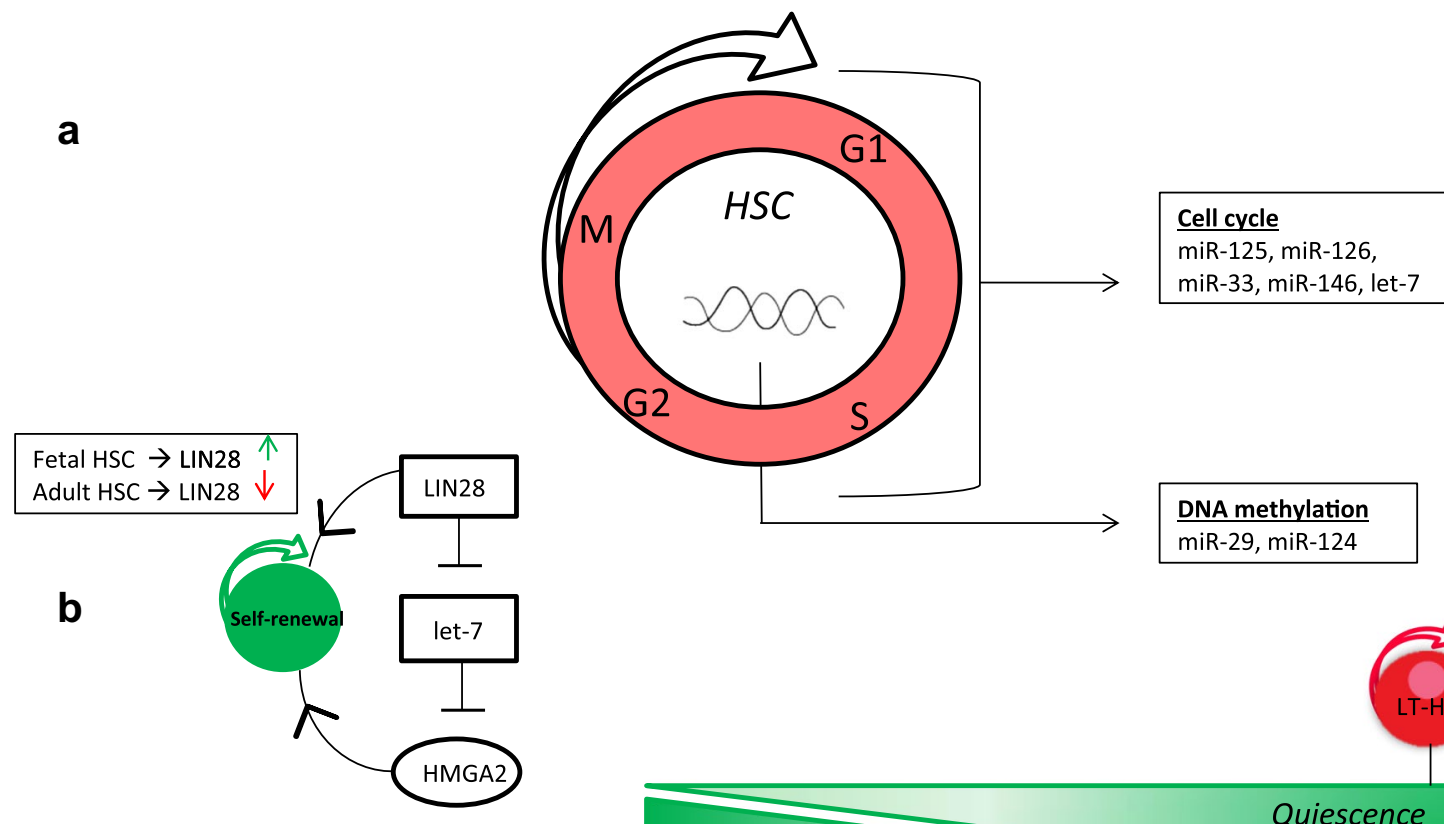

C

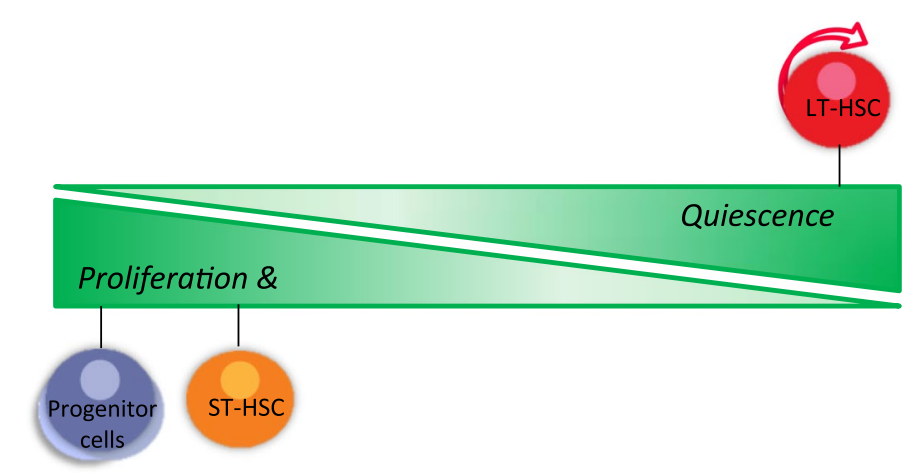

Fig. 2 miRNA-mediated regulation of cell cycle in HSCs. (a) The schematic describes miRNAs (e.g. miR-125, miR-126, miR-33, miR146 and let-7) with critical roles in the cell cycle regulation in adult HSCs by directly targeting cell cycle components. Furthermore, miR29 and miR-124, which target components involved in DNA methylation, indirectly influence the expression of cell cycle-associated genes. (b) The LIN28-HMGA2 feed-forward loop is among the most important mechanisms that drive fetal HSC self-renewal. LIN28 is highly expressed in fetal HSCs compared to adult HSCs. As LIN28 directly inhibits let-7 expression, this indicates the important role of miRNA let-7 upon stem cell differentiation. Decreased level of let-7 has resulted in higher expression of $H M G A 2$, which induces selfrenewal. Additionally, LIN28 can acts independently of the let-7 fam-

and differentiation capacity [104]. The transition of HSCs into progenitor cells is related with a switch from quiescent into rapid proliferating cells, and subsequently an alteration in expression of surface makers (Fig. 2c). Therefore, the expression of cell cycle related miRNAs in exclusively progenitor cells is likely to be involved in the alteration of cell cycle duration [70]. One of the enhanced expressed miRNAs in LT-HSCs is the miR-125 cluster (miR-125a, miR125b1, miR-125b2). The expression of miR-125 has been shown to be associated with self-renewal and expansion of the stem cell population in vivo [105-107]. Furthermore, miR-29a has been revealed to regulate the G1/S transition in hematopoietic progenitor stem cells. MiR-29a promotes the self-renewal capacity by targeting a subset of genes that ily and contributes to self-renewal $[95,96]$. (c) Adult HSCs are a heterogeneous population that differ in self-renewal and differentiation capacity based on their surface markers. Long-term HSCs (LT-HSCs) are predominantly quiescent $\left(\mathrm{c}-\mathrm{kit}^{+} \mathrm{Sca}_{-}{ }^{+} \mathrm{Lin}^{-} \mathrm{Flk}-2^{-} \mathrm{CD} 34^{-}\right)$ [103]. However, a large fraction of short term-HSCs (c-kit ${ }^{+} \mathrm{Sca}^{+}{ }^{+}$ $\mathrm{Lin}^{-}$Flk-2- $\mathrm{CD}^{-} 4^{+}$) gives rise to the differentiated progeny, and also shows greater cell proliferation capacity than LT-HSCs [102, 103]. Progenitor cells are associated with proliferation and differentiation into hematopoietic lineages. KSL (c-kit $\left.{ }^{+} \mathrm{Sca}_{-}{ }^{+} \mathrm{Lin}^{-}\right)$with high $\mathrm{CD} 150^{+}$expression may give predominant rise to myeloid linages, whereas KSL-CD150- are more likely to a lymphoid outcome [104]. Several studies also demonstrate that specific miRNAs are differentially expressed among HSCs and progenitor cells

are involved in cell cycle progression, including $C D C 42 E P 2$ and $H B P 1$ [108]. Recently, Lechman et al. demonstrated that miR-126 can control the cell cycle progression by targeting the PI3K/AKT/MTOR pathway [109]. They showed that overexpression of miR-126 results in an increased percentage of quiescent cells, whereas a knockdown of miR-126 lead to enhanced proliferation and differentiation of HSCs [109-111].

Additionally, previous studies have suggested miR-125 and miR-126 as potential target treatment for acute myeloid leukemia (AML) $[112,113]$. An indication for the potential therapeutic function is based on the alternated expression of these miRNAs between $\mathrm{CD} 34^{+} \mathrm{CD} 38^{-} \mathrm{HSC}$ and $\mathrm{CD} 34^{+} \mathrm{CD} 38^{-}$leukemic stem cells. A reduction of miR-126 
stimulates the PI3K/AKT/MTOR pathway in HSCs and will result in an increased number of HSCs, while this effect decreases the self-renewal capacity in $\mathrm{CD} 34^{+} \mathrm{CD} 38^{-}$leukemic stem cells [112]. Although this miRNA-based treatment holds promising capacity to in vivo experiments, issues with respect to toxicity and delivery need to be solved before application in AML patients [112].

Mesenchymal stem cells (MSCs) are multipotent cells that originate from bone marrow stroma, but are present in various tissues such as adipose tissue, bone, skeletal muscle, cartilage and tendon [114]. Evidence suggests that miRNAs are closely involved in the regulation of MSC differentiation into specific cell lineages [101, 115-117]. The role of miRNAs in proliferation and cell cycle regulation of human MSCs has been investigated through Drosha and Dicer knockdown studies [118]. These studies have shown a significant increase in the number of cells in G1 phase and a reduced proliferation rate of MSCs [118]. In the same study, Drosha knockdown in MSCs resulted in a decrease of $\mathrm{pRb}$ and an increase in p16 and p15 levels [118]. Other studies have been implicated miR-16 and miR-143 in the regulation of MSC proliferation and differentiation. In this regard, miR16 has been shown to inhibit MSC proliferation and induce cell cycle arrest by targeting cyclin E [119]. Likewise, miR-143 targets ERK5 (member of MAPK family), which itself decreases the expression of cyclin D and CDK6. This reduces cell entry into $S$ phase, suggesting miR-143 to be a negative regulator of the cell cycle progression [120,121]. Moreover, a number of miRNAs have determined to control the differentiation into specific linages, such as osteoblasts [122]. For example, Peng et al. demonstrated that miRNAs promote the osteogenic differentiation of MSCs via $B M P$, $W N T / \beta$-catenin and NOTCH signaling pathways. Among them, miR-27 promotes differentiation by targeting $A P C$, which modulates the G2/M transition [122, 123]. On the other hand, miR-27 expression is shown to be downregulated upon adipocyte differentiation [124, 125]. Several cell cycle associated genes, including ERK1/2, ERK5, TGF- $\beta 1$ and $K L F 5$ are related to adipocyte differentiation, which is explained by miRNA regulation [126]. Notably, miR-143, miR-448 and miR-375 have been reported as negative regulators and miR-21 as positive regulator of adipocyte differentiation [126].

\section{Cancer Stem Cells (CSCs)}

Altered expression and molecular abnormalities of the cellcycle-regulatory proteins, such as pRB, p53, CDKs, CDKIs and cyclins, play a central role in cancer initiation and progression [17, 127-129]. Notably, it has been suggested that a class of cancer cells with characteristics of stem cells, socalled cancer stem cells (CSCs), are responsible for tumor initiation, invasion, metastasis and chemoresistance [130,
131]. As discussed previously in this review, miRNAs have the ability to suppress apoptosis and promote proliferation by interplaying with the cell cycle components. Therefore, miRNAs and CSCs share common properties with respect to tumorigenesis. The transcriptional levels of several miRNAs have shown to vary between normal stem cells and CSCs [132]. Furthermore, associations between either cell cycle components including cyclins and transcription factors or miRNA expression and specific CSC markers have been investigated [133, 134]. Hence, miRNAs as regulators of CSCs have gain attention in recent years in multiple fields of research [131, 133, 135, 136]. The associations between miRNAs expression and various cancers are summarized in Table 2. In the following paragraph, some of the main CSCrelated miRNAs will be discussed.

The miR-17-92 cluster affects the cell cycle by targeting E2F-1 and cyclin D as well as it cooperates with the oncogene MYC to prevent apoptosis in CSCs [169-172]. Li et al. investigated the miR-17-92 target genes involved in the MYC suppression. They demonstrated that the functionalities of the miR-17-92 target genes rely on multiple DNA replication, cell cycle regulation, chromosome organization, RNA transcription or protein metabolism [51]. Similarly, this miRNA cluster is shown to coordinate the timing of cell cycle progression by modulating expression of BMII, PTEN, RBL2 and $\mathrm{p} 21$ [154, 173-176].

Other important regulators of CSCs are the members of the let-7 family. Evidence suggests that let-7 is among the most important miRNAs involved in tumor progression and chemoresistance [131, 177]. The expression of the let-7 family is reduced in various types of tumor cells, including breast, head and neck squamous (HNSCC), lung, pancreatic, neuroblastoma cells, among others [131, 133, 178, 179]. Accordingly, decreased expression of let-7 has resulted in overexpression of oncogenes MYC, RAS, HMGA 2 and BLIMP1 [115, 177, 180]. Furthermore, members of the let-7 family have been recognized as negative regulators of PTEN that inactivate the PI3K/AKT/MTOR pathway. The let-7 family has also shown to be involved in suppressing the epithelial-to-mesenchymal transition (EMT), which is related to metastasis and chemoresistance and therefore a characteristic of CSCs [131, 177]. Multiple genes involved in cell cycle progression are suggested to be targets for the let-7 family. The latter include cyclin D, cyclin A, CDK1,CDK2, CDK4,CDK6,CDK8 and $C D C 25 A[115,177,180]$. Also, it has been shown that the RNA binding protein LIN28 inhibits let-7 by stimulating cellular proliferation via cyclin $\mathrm{D}, C D K 2$ and $C D C 25 A$ and thereby contribute to the maintenance of stemness characteristics of CSCs [46, 181]. LIN28 has been recognized as an oncogene, as it promotes tumor progression by repressing let-7 [177]. Previous studies based on let-7 expression and tumor progression display that ectopic expression of 
Table 2 miRNAs associated with the cell cycle progression in cancer stem cells

\begin{tabular}{|c|c|c|c|c|c|}
\hline Cancer type & miRNA ID & Potential target gene(s) & Exp. of miRNA & Reported biological effect & Reference \\
\hline \multirow[t]{8}{*}{ Breast } & let-7 & $\operatorname{LIN} 28$ & Downregulated & $\begin{array}{l}\text { Upregulation of } L I N 28 \text { results in sup- } \\
\text { porting } R A S, M Y C \text { and } H M G A 2\end{array}$ & {$[137]$} \\
\hline & miR-21 & PTEN & Upregulated & $\begin{array}{l}\text { Promote PI3K/AKT signaling activa- } \\
\text { tion through directly inhibiting } \\
\text { PTEN expression }\end{array}$ & {$[138]$} \\
\hline & $\operatorname{miR}-221 / 222$ & PTEN & Upregulated & $\begin{array}{l}\text { Promote AKT/NF- } \kappa / \mathrm{COX}-2 \text { pathway } \\
\text { by targeting } P T E N\end{array}$ & [139] \\
\hline & miR-93 & $\begin{array}{l}J A K 1, S O X 4, S T A T 3, A K T, E Z H 1, \\
\quad H M G A 2\end{array}$ & Upregulated & Regulate CSC proliferation & {$[140]$} \\
\hline & $\operatorname{miR}-34$ & CDK4, CDK6, NOTCH1 & Downregulated & Regulate p53 & [141] \\
\hline & miR-16 & BMII & Upregulated & $\begin{array}{l}\text { Inhibit DNA repair by repressing } \\
\text { BMII }\end{array}$ & [142] \\
\hline & miR-200 & ZEB1, ZEB2, WNT-signaling & Downregulated & Reduction of EMT & [143] \\
\hline & $\operatorname{miR}-494-3 p$ & $P A K 1$ & Downregulated & $\begin{array}{l}\text { Inhibit proliferation via MAPK by } \\
\text { targeting } P A K 1\end{array}$ & [144] \\
\hline \multirow[t]{5}{*}{ Liver (HCC) } & $\operatorname{miR}-34$ & Cyclin D1, BCL2 & Downregulated & Regulate p53 & {$[145]$} \\
\hline & $\operatorname{miR}-365$ & $B C L 2$ & Upregulated & Apoptosis & [146] \\
\hline & $\operatorname{miR}-31$ & $H D C A 2, C D K 2$ & Downregulated & $\begin{array}{l}\text { Induction of } \mathrm{p} 16 \text { and } \mathrm{p} 21 . \text { Repression } \\
\text { of cyclin } \mathrm{D}, \mathrm{CDK} 4, \mathrm{CDK} 2\end{array}$ & [147] \\
\hline & miR-26a & $E Z H 2$ & Upregulated & Reduction of EMT & [148] \\
\hline & miR-150 & $G A B 1$ & Downregulated & $\begin{array}{l}\text { Suppress proliferation and invasion } \\
\text { via MAPK pathway by targeting } \\
G A B 1 \text { and } E R K 1 / 2\end{array}$ & [149] \\
\hline Head and Neck & let-7 & $A B C B 1$ & Downregulated & Reduction of cell proliferation & {$[150]$} \\
\hline \multirow[t]{5}{*}{ Pancreatic } & let-7 & $\operatorname{LIN} 28$ & Downregulated & $\begin{array}{l}\text { Inhibit EMT, induces cell cycle arrest } \\
\text { when LIN28 is reduced }\end{array}$ & [151] \\
\hline & $\operatorname{miR}-21$ & PTEN, PDCD4 & Upregulated & Promote metastasis & {$[152]$} \\
\hline & miR-203 & $Z E B 1, Z E B 2$ & Downregulated & Reduction of EMT & [153] \\
\hline & $\operatorname{miR}-34$ & BCL2, NOTCH1/2 & Downregulated & Regulate p53 & [136] \\
\hline & miR-17-92 & $p 21, p 57, T B X 3$ & Downregulated & $\begin{array}{l}\text { Maintain stemness characteristics in } \\
\text { pancreatic CSC. Downregulation } \\
\text { of } M Y C\end{array}$ & {$[154]$} \\
\hline \multirow[t]{4}{*}{ Prostate } & let-7 & $\operatorname{LIN} 28$ & Upregulated & Upregulating cell cycle via cyclin D1 & {$[155]$} \\
\hline & $\operatorname{miR}-100$ & $C D K 6, R B 1, m T O R$ & Downregulated & Regulation of cell growth & {$[156]$} \\
\hline & miR-34 & $\begin{array}{l}\text { Cyclin D1, CDK4, CDK6, c-MET, } \\
\text { CD44 }\end{array}$ & Downregulated & Mediating p53. Tumor metastasis & {$[157]$} \\
\hline & $\operatorname{miR}-221 / 222$ & p27/Kip1 & Upregulated & $\begin{array}{l}\text { Regulate activation of cyclin } \mathrm{E} \text { and } \\
\text { cyclin D }\end{array}$ & {$[158]$} \\
\hline \multirow[t]{6}{*}{ Glioblastoma } & miR-124 & $C D K 6$ & Upregulated & Inhibit cell proliferation & [159] \\
\hline & miR-137 & CDK6 & Upregulated & Inhibit cell proliferation & [160] \\
\hline & $\operatorname{miR}-128$ & $B M I 1$ & Upregulated & $\begin{array}{l}\text { Decreasing cell proliferation in } I D H I \\
\text { mutant glioma }\end{array}$ & {$[161]$} \\
\hline & $\operatorname{miR}-23 b$ & $H M G A 2$ & Upregulated & $\begin{array}{l}\text { Cell cycle arrest and proliferation } \\
\text { inhibition }\end{array}$ & {$[162]$} \\
\hline & $\operatorname{miR}-125 b$ & $C D K 6, E 2 F 3, C D C 25 A$ & Downregulated & Induce $\mathrm{G} 1 / \mathrm{S}$ cell cycle arrest & [163] \\
\hline & miR-34 & BCL2, NOTCH1 & Downregulated & $\begin{array}{l}\text { Targeting p53. Anti-apoptotic, } \\
\text { increase cell proliferation }\end{array}$ & {$[164]$} \\
\hline \multirow[t]{4}{*}{ Lung } & miR-605 & LATS2 & Upregulated & $\begin{array}{l}\text { Promote cell proliferation, migration } \\
\text { and invasion }\end{array}$ & {$[165]$} \\
\hline & let-7 & $\begin{array}{l}\text { KRAS, MYC, CDK6 HMGA2, } \\
\quad T G F B R 2\end{array}$ & Downregulated & $\begin{array}{l}\text { Suppression of multiple oncogenic } \\
\text { members }\end{array}$ & [166] \\
\hline & $\operatorname{miR}-21$ & MDM4 & Upregulated & Repress $M D M 4$ to activate $\mathrm{p} 53$ & {$[167]$} \\
\hline & $\mathrm{miR}-15 \mathrm{a} / \mathrm{miR}-16$ & $R B$ & Downregulated & Cell cycle arrest & [168] \\
\hline
\end{tabular}


let-7 was sufficient enough to inhibit proliferation and clonal expansion in vitro and tumor recurrence in prostate cancer cells in vivo [173].

The next miRNA family, consisting of miR-34a, $b$, and $\mathrm{c}$, is well-studied regarding to cell cycle progression and its expression is downregulated in several types of cancer cells including lung adenocarcinomas, colon cancer and liver cancer (HCC) [141, 167, 182-185]. MiR-34a induces both G1/S cell cycle arrest and cell senescence [167]. Reduced expression of miR-34 has been associated with enhanced levels of $B C L 2$ and NOTCH, which are target genes for tumor suppressor gene p53 [131, 135, 167]. Similarity, miR-34 promotes apoptosis via Caspase 3, and therefore increases sensitivity for anti-cancer treatment [135]. By regulating CDK6, cyclin D1 and E2F, miR-34 negatively affects cell cycle progression in colon cancer cells $[131,184,185]$. In addition, miR-34 represses pluripotency genes inclusive of NANOG, SOX2 and MYC [135]. Thus, overexpression of this miRNA family may cause an accumulated percentage of cells in the G0/G1 phase and significantly reduces the population of cells in the $S$ phase.

MiR-31 has also shown to be inversely correlated with metastasis, since its high expression in liver cancer is linked with a poor prognosis in patients. Kim et al. showed that ectopic expression of miR-31 evokes an overexpression of CDK2 and HDAC2 [147]. They demonstrated that through abnormal expression of $H D A C 2$, negative cell cycle regulators p16/INK4A, p19/INK4D and p21/Cip1 are induced.

Furthermore, an oncogenic role has been reported for the miR-15a/16 family in chronic lymphocytic leukemia (CLL), pituitary adenomas, and gastric cancer [186, 187]. On the other hand, this miRNA family is shown to act as a tumor suppressor in a subset of B cell lymphoma, where deletion of this miRNA family in a subset of B cell lymphomas resulted in chronic lymphocytic leukemia in mice [188]. In fact, miR-15a and miR-16 display an anti-proliferative potential in this type of cancer stem cell by silencing $B C L 2$ and activating the intrinsic apoptosis pathway $[189,190]$. In addition, some studies revealed the miR-15a/16 family as regulator of various cyclins, including cyclins D1 and D2 and cyclin E1, and pRb [168, 180, 191].

An additional miRNA that has been suggested as an oncomiR, through targeting multiple signaling pathways, is miR-21 [33]. Upregulation of miR-21 has an oncogenic potential in a wide range of tumors including lung, breast, pancreatic, brain and colon cancers, through downregulation of p21 and tumor suppressor genes PTEN and PDCD4 [33, 192-194]. MiR-26a is also suggested as a negative regulator of cancer cell proliferation by targeting cyclins D2 and $\mathrm{E} 2$, and CDK6. It has been established that overexpression of miR-26a results in cell cycle arrest in human liver cancer cells in vitro $[195,196]$.

\section{Concluding Remarks and Future Prospects}

A growing body of evidence has addressed the potential role of miRNAs in cell cycle regulation of stem cells. In light of recent discoveries about the role miRNAs in self-renewal, proliferation and differentiation, it is crucial to unravel the complex mechanisms and molecular interactions within this field of research. In this review, we outlined the most established miRNAs involved in the cell cycle progression of stem cells. We highlighted several clusters and single miRNAs that may control selfrenewal and maintenance of the pluripotency status in ESCs. These include but are not limited to ESCC miRNAs (miR-290-295, miR-302, miR-17-92, miR-106b-25 and miR-106a-363), which are functionally upregulated to suppress negative regulators and to enhance pluripotent transcription factors such as $N A N O G$ and $M Y C$ in an epigenetic manner [45].

Furthermore, specific profiles of miRNA expression in distinct somatic stem cell lineages are linked with developmental control by keeping several multipotent stem cells (e.g. HSCs) in a quiescent state. Previous research based on Dicer-knockout and Dgcr8-deficient mice have elucidated that miRNAs are expressed temporally and spatially among somatic stem cells and precursor cells [37]. It is crucial for somatic stem cells like HSCs to keep a balance between quiescent state and proliferating state. To accomplish that, a complex network of miRNAs exists that inhibit positive cell cycle regulators such as cyclins, as well as miRNAs modulating anti-apoptotic properties. Complex interactions between miRNAs, transcription factors and cell cycle-mediated components may control the gene expression upon differentiation of multipotent stem cells into progenitor cells and mature cells.

It is clear that abnormalities in the cell cycle are related to tumorigenesis and previous studies have highlighted the significant importance of miRNAs in the regulation of CSCs [132]. Since CSC features are linked to metastasis, invasion and therapeutic resistance, it is of main clinical relevance to unravel the interactive properties between CSC-related miRNAs and cell cycle components. From the data available so far it appears that there is a great overlapping role between ESCC miRNAs that are expressed in both ESCs and CSCs. However, a subset of miRNAs is characterized as tumor suppressor genes as they are expressed regarding anti-proliferating features by targeting oncogenic pathways including MYC. Those miRNAs, including let-7, miR-34, miR-31 and miR-17-92 family, are of major interest since they are associated with a good prognosis in cancer patients. Future research should focus on targeting the CSC-related miRNAs involved in oncogenic pathways since they will provide a more effective 
approach to exterminate CSCs. Subsequently, a miRNA based method for cancer treatment is highly target driven as it interferes with specific abnormalities in the cell cycle within the tumor microenvironment.

Collectively, this review marks several noteworthy insights into the cell cycle regulation of stem cells by miRNAs. Understanding the tightly regulated molecular networks in which miRNAs are interacting, will greatly enhance our knowledge in the development of both healthy and disease states of the human body.

\section{Compliance with Ethical Standards}

Conflict of Interest The authors declare no potential conflicts of interest.

Open Access This article is distributed under the terms of the Creative Commons Attribution 4.0 International License (http://creativeco mmons.org/licenses/by/4.0/), which permits unrestricted use, distribution, and reproduction in any medium, provided you give appropriate credit to the original author(s) and the source, provide a link to the Creative Commons license, and indicate if changes were made.

\section{References}

1. Draper, J. S., et al. (2004). Culture and characterization of human embryonic stem cells. Stem Cells and Development, 13(4), 325-336.

2. Xie, X., Teknos, T. N., \& Pan, Q. (2014). Are all cancer stem cells created equal? Stem Cells Translational Medicine, 3(10), $1111-1115$.

3. Harashima, H., Dissmeyer, N., \& Schnittger, A. (2013). Cell cycle control across the eukaryotic kingdom. Trends in Cell Biology, 23(7), 345-356.

4. Wilson, A., et al. (2008). Hematopoietic stem cells reversibly switch from dormancy to self-renewal during homeostasis and repair. Cell, 135(6), 1118-1129.

5. Blomen, V. A., \& Boonstra, J. (2007). Cell fate determination during G1 phase progression. Cellular and Molecular Life Sciences, 64(23), 3084-3104.

6. She, S., et al. (2017). Cell cycle and pluripotency: convergence on octamer binding transcription factor 4 (Review). Molecular Medicine Reports, 16(5), 6459-6466

7. Pauklin, S., \& Vallier, L. (2013). The cell-cycle state of stem cells determines cell fate propensity. Cell, 155(1), 135-147.

8. Dalton, S. (2015). Linking the cell cycle to cell fate decisions. Trends in Cell Biology, 25(10), 592-600.

9. Coronado, D., et al. (2013). A short G1 phase is an intrinsic determinant of naive embryonic stem cell pluripotency. Stem Cell Research, 10(1), 118-131.

10. Conklin, J. F., Baker, J., \& Sage, J. (2012). The RB family is required for the self-renewal and survival of human embryonic stem cells. Nature Communications, 3, 1244.

11. Yeo, H. C., et al. (2011). Integrated transcriptome and binding sites analysis implicates E2F in the regulation of self-renewal in human pluripotent stem cells. PLoS One, 6(11), e27231.

12. Hindley, C., \& Philpott, A. (2013). The cell cycle and pluripotency. Biochemical Journal, 451(2), 135-143.

13. Lu, Z., \& Hunter, T. (2010). Ubiquitylation and proteasomal degradation of the p21(Cip1). p27(Kip1) and p57(Kip2) CDK inhibitors. Cell Cycle, 9(12), 2342-2352.
14. Fabbro, M., et al. (2004). BRCA1-BARD1 complexes are required for $\mathrm{p} 53 \mathrm{Ser}-15$ phosphorylation and a G1/S arrest following ionizing radiation-induced DNA damage. The Journal of Biological Chemistry, 279(30), 31251-31258.

15. Hyun, S. Y., \& Jang, Y. J. (2015). p53 activates G(1) checkpoint following DNA damage by doxorubicin during transient mitotic arrest. Oncotarget, 6(7), 4804-4815.

16. Lanni, J. S., \& Jacks, T. (1998). Characterization of the p53-dependent postmitotic checkpoint following spindle disruption. Molecular and Cellular Biology, 18(2), 1055-1064.

17. Bieging, K. T., Mello, S. S., \& Attardi, L. D. (2014). Unravelling mechanisms of p53-mediated tumour suppression. Nature Reviews Cancer, 14(5), 359-370.

18. Jain, A. K., et al. (2012). p53 regulates cell cycle and microRNAs to promote differentiation of human embryonic stem cells. PLoS Biol, 10(2), e1001268.

19. Bueno, M. J., \& Malumbres, M. (2011). MicroRNAs and the cell cycle. Biochimica et Biophysica Acta, 1812(5), 592-601.

20. Wang, Y., \& Blelloch, R. (2009). Cell cycle regulation by MicroRNAs in embryonic stem cells. Cancer Research, 69(10), 4093-4096.

21. Wang, Y., \& Blelloch, R. (2011). Cell cycle regulation by microRNAs in stem cells. Results and Problems in Cell Differentiation, 53, 459-472.

22. Yu, Z., et al. (2012). miRNAs regulate stem cell self-renewal and differentiation. Frontiers in Genetics, 3, 191.

23. Braun, C. J., et al. (2008). p53-Responsive micrornas 192 and 215 are capable of inducing cell cycle arrest. Cancer Research, 68(24), 10094-10104.

24. Lee, R. C., Feinbaum, R. L., \& Ambros, V. (1993). The C. elegans heterochronic gene lin-4 encodes small RNAs with antisense complementarity to lin-14. Cell, 75(5), 843-854.

25. Kozomara, A., \& Griffiths-Jones, S. (2014). miRBase: annotating high confidence microRNAs using deep sequencing data. Nucleic Acids Research, 42(Database issue), D68-73.

26. Esquela-Kerscher, A., \& Slack, F. J. (2006). Oncomirs - microRNAs with a role in cancer. Nature Reviews Cancer, 6(4), 259-269.

27. van Rooij, E., \& Olson, E. N. (2012). MicroRNA therapeutics for cardiovascular disease: opportunities and obstacles. Nature Reviews Drug Discovery, 11(11), 860-872.

28. Ghanbari, M., et al. (2014). A genetic variant in the seed region of miR-4513 shows pleiotropic effects on lipid and glucose homeostasis, blood pressure, and coronary artery disease. Human Mutation, 35(12), 1524-1531.

29. van Rooij, E., et al. (2006). A signature pattern of stress-responsive microRNAs that can evoke cardiac hypertrophy and heart failure. Proceedings of the National Academy of Sciences of the United States of America, 103(48), 18255-18260.

30. Goren, Y., et al. (2012). Serum levels of microRNAs in patients with heart failure. European Journal of Heart Failure, 14(2), 147-154.

31. Karolina, D. S., et al. (2012). Circulating miRNA profiles in patients with metabolic syndrome. The Journal of Clinical Endocrinology and Metabolism, 97(12): p. E2271-6.

32. Ghanbari, M., et al. (2015). Genetic variations in microRNAbinding sites affect microRNA-mediated regulation of several genes associated with cardio-metabolic phenotypes. Circulation Cardiovascular Genetics, 8(3), 473-486.

33. Malumbres, M. (2013). miRNAs and cancer: an epigenetics view. Molecular Aspects of Medicine, 34(4), 863-874.

34. Reinhart, B. J., et al. (2000). The 21-nucleotide let-7 RNA regulates developmental timing in Caenorhabditis elegans. Nature, 403(6772), 901-906. 
35. Shim, J., \& Nam, J. W. (2016). The expression and functional roles of microRNAs in stem cell differentiation. BMB Reports, 49(1), 3-10.

36. Huang, X. A., \& Lin, H. (2012). The miRNA regulation of stem cells. Wiley Interdisciplinary Reviews: Membrane Transport and Signaling, 1(1), 83-95.

37. Wang, Y., et al. (2007). DGCR8 is essential for microRNA biogenesis and silencing of embryonic stem cell self-renewal. Nature Genetics, 39(3), 380-385.

38. Bernstein, E., et al. (2003). Dicer is essential for mouse development. Nature Genetics, 35(3), 215-217.

39. Dalton, S. (2009). Exposing hidden dimensions of embryonic stem cell cycle control. Cell Stem Cell, 4(1), 9-10.

40. Stein, G. S., et al. (2006). An architectural perspective of cellcycle control at the G1/S phase cell-cycle transition. Journal of Cellular Physiology, 209(3), 706-710.

41. Sengupta, S., et al. (2009). MicroRNA 92b controls the G1/S checkpoint gene p57 in human embryonic stem cells. Stem Cells, 27(7), 1524-1528.

42. Kareta, M. S., et al. (2015). Inhibition of pluripotency networks by the $\mathrm{Rb}$ tumor suppressor restricts reprogramming and tumorigenesis. Cell Stem Cell, 16(1), 39-50.

43. Becker, K. A., et al. (2006). Self-renewal of human embryonic stem cells is supported by a shortened G1 cell cycle phase. Journal of Cellular Physiology, 209(3), 883-893.

44. Hao, J., Duan, F. F., \& Wang, Y. (2017). MicroRNAs and RNA binding protein regulators of microRNAs in the control of pluripotency and reprogramming. Current Opinion in Genetics \& Development, 46, 95-103.

45. Li, N., et al. (2017). microRNAs: important regulators of stem cells. Stem Cell Research \& Therapy, 8(1), 110.

46. Lichner, Z., et al. (2011). The miR-290-295 cluster promotes pluripotency maintenance by regulating cell cycle phase distribution in mouse embryonic stem cells. Differentiation, 81(1), 11-24.

47. Yuan, K., et al. (2017). The miR-290-295 cluster as multifaceted players in mouse embryonic stem cells. Cell \& Bioscience, $7(38)$.

48. Wang, Y., et al. (2008). Embryonic stem cell-specific microRNAs regulate the G1-S transition and promote rapid proliferation. Nature Genetics, 40(12), 1478-1483.

49. Calabrese, J. M., et al. (2007). RNA sequence analysis defines Dicer's role in mouse embryonic stem cells. Proceedings of the National Academy of Sciences of the United States of America, 104(46), 18097-18102.

50. Houbaviy, H. B., Murray, M. F., \& Sharp, P. A. (2003). Embryonic stem cell-specific microRNAs. Developmental Cell, 5(2), $351-358$

51. Li, Y., et al. (2014). MYC through miR-17-92 suppresses specific target genes to maintain survival, autonomous proliferation, and a neoplastic state. Cancer Cell, 26(2), 262-272.

52. Melton, C., Judson, R. L., \& Blelloch, R. (2010). Opposing microRNA families regulate self-renewal in mouse embryonic stem cells. Nature, 463(7281), 621-626.

53. Takahashi, K., \& Yamanaka, S. (2006). Induction of pluripotent stem cells from mouse embryonic and adult fibroblast cultures by defined factors. Cell, 126(4), 663-676.

54. Zheng, G. X., et al. (2011). A latent pro-survival function for the mir-290-295 cluster in mouse embryonic stem cells. PLoS Genet, 7(5), e1002054.

55. Kanellopoulou, C., et al. (2015). Reprogramming of polycombmediated gene silencing in embryonic stem cells by the miR290 family and the methyltransferase Ash11. Stem Cell Reports, 5(6), 971-978.
56. Richly, H., Aloia, L., \& Di Croce, L. (2011). Roles of the Polycomb group proteins in stem cells and cancer. Cell Death \& Disease, 2, e204.

57. Aguda, B. D., et al. (2008). MicroRNA regulation of a cancer network: consequences of the feedback loops involving miR-17-92, E2F, and Myc. Proceedings of the National Academy of Sciences of the United States of America, 105(50), 19678-19683.

58. Ivanovska, I., et al. (2008). MicroRNAs in the miR-106b family regulate $\mathrm{p} 21 / \mathrm{CDKN} 1 \mathrm{~A}$ and promote cell cycle progression. Molecular and Cellular Biology, 28(7), 2167-2174.

59. Kuo, C. H., et al. (2012). A novel role of miR-302/367 in reprogramming. Biochemical and Biophysical Research Communications, 417(1), 11-16.

60. Card, D. A., et al. (2008). Oct4/Sox2-regulated miR-302 targets cyclin D1 in human embryonic stem cells. Molecular and Cellular Biology, 28(20), 6426-6438.

61. Anokye-Danso, F., et al. (2011). Highly efficient miRNA-mediated reprogramming of mouse and human somatic cells to pluripotency. Cell Stem Cell, 8(4), 376-388.

62. Lipchina, I., Studer, L., \& Betel, D. (2012). The expanding role of miR-302-367 in pluripotency and reprogramming. Cell Cycle, 11(8), 1517-1523.

63. Dolezalova, D., et al. (2012). MicroRNAs regulate p21(Waf1/ Cip1) protein expression and the DNA damage response in human embryonic stem cells. Stem Cells, 30(7), 1362-1372.

64. Liang, Y., et al. (2012). Mechanism of folate deficiency-induced apoptosis in mouse embryonic stem cells: Cell cycle arrest/apoptosis in G1/G0 mediated by microRNA-302a and tumor suppressor gene Lats2. The International Journal of Biochemistry \& Cell Biology, 44(11), 1750-1760.

65. Fu, Y., et al. (2017). Characterization and expression of lin-28a involved in lin28/let-7signal pathway during early development of P. olivaceus. Fish Physiol Biochem.

66. Rybak, A., et al. (2008). A feedback loop comprising lin-28 and let-7 controls pre-let-7 maturation during neural stem-cell commitment. Nature Cell Biology, 10(8), 987-993.

67. Qi, J., et al. (2009). microRNAs regulate human embryonic stem cell division. Cell Cycle, 8(22), 3729-3741.

68. Bhattacharya, A., et al. (2013). Regulation of cell cycle checkpoint kinase WEE1 by miR-195 in malignant melanoma. Oncogene, 32(26), 3175-3183.

69. Shenoy, A., \& Blelloch, R. H. (2014). Regulation of microRNA function in somatic stem cell proliferation and differentiation. Nature Reviews Molecular Cell Biology, 15(9), 565-576.

70. Arnold, C. P., et al. (2011). MicroRNA programs in normal and aberrant stem and progenitor cells. Genome Research, 21(5), 798-810.

71. Andersson, T., et al. (2010). Reversible block of mouse neural stem cell differentiation in the absence of dicer and microRNAs. PLoS One, 5(10), e13453.

72. Wang, D., et al. (2013). MicroRNA-205 controls neonatal expansion of skin stem cells by modulating the PI(3)K pathway. Nature Cell Biology, 15(10), 1153-1163.

73. Jackson, S. J., et al. (2013). Rapid and widespread suppression of self-renewal by microRNA-203 during epidermal differentiation. Development, 140(9), 1882-1891.

74. Antonini, D., et al. (2010). Transcriptional repression of miR-34 family contributes to p63-mediated cell cycle progression in epidermal cells. The Journal of Investigative Dermatology, 130(5), 1249-1257.

75. Nagosa, S., et al. (2017) microRNA-184 induces a commitment switch to epidermal differentiation. Stem Cell Reports, 9(6), 1991-2004. 
76. Ahmed, M. I., et al. (2014). MicroRNA-214 controls skin and hair follicle development by modulating the activity of the Wnt pathway. The Journal of Cell Biology, 207(4), 549-567.

77. Zhao, C., et al. (2009). A feedback regulatory loop involving microRNA-9 and nuclear receptor TLX in neural stem cell fate determination. Nature Structural and Molecular Biology, 16(4), 365-371.

78. Sun, G., et al. (2011). miR-137 forms a regulatory loop with nuclear receptor TLX and LSD1 in neural stem cells. Nature Communications, 2, 529.

79. Liu, C., et al. (2010). Epigenetic regulation of miR-184 by MBD1 governs neural stem cell proliferation and differentiation. Cell Stem Cell, 6(5), 433-444.

80. Liu, C., et al. (2013). An epigenetic feedback regulatory loop involving microRNA-195 and MBD1 governs neural stem cell differentiation. PLoS One, 8(1), e51436.

81. Cheng, L. C., et al. (2009). miR-124 regulates adult neurogenesis in the subventricular zone stem cell niche. Nature Neuroscience, 12(4), 399-408.

82. Makeyev, E. V., et al. (2007). The MicroRNA miR-124 promotes neuronal differentiation by triggering brain-specific alternative pre-mRNA splicing. Molecular Cell, 27(3), 435-448.

83. Visvanathan, J., et al. (2007). The microRNA miR-124 antagonizes the anti-neural REST/SCP1 pathway during embryonic CNS development. Genes and Development, 21(7), 744-749.

84. Liu, Z., et al. (2017). Elevated p53 activities restrict differentiation potential of microRNA-deficient pluripotent stem cells. Stem Cell Reports, 9(5), 1604-1617.

85. Wang, J., Chen, T., \& Shan, G. (2017). miR-148b regulates proliferation and differentiation of neural stem cells via Wnt/ beta-catenin signaling in rat ischemic stroke model. Frontiers in Cellular Neuroscience, 11, 329.

86. Wang, J., et al. (2017). MicroRNA1385p regulates neural stem cell proliferation and differentiation in vitro by targeting TRIP6 expression. Molecular Medicine Reports, 16(5), 7261-7266.

87. Crist, C. G., et al. (2009). Muscle stem cell behavior is modified by microRNA-27 regulation of Pax3 expression. Proceedings of the National Academy of Sciences of the United States of America, 106(32), 13383-13387.

88. Sarkar, S., Dey, B. K., \& Dutta, A. (2010). MiR-322/424 and -503 are induced during muscle differentiation and promote cell cycle quiescence and differentiation by down-regulation of Cdc25A. Molecular Biology of the Cell, 21(13), 2138-2149.

89. Chen, J. F., et al. (2010). microRNA-1 and microRNA-206 regulate skeletal muscle satellite cell proliferation and differentiation by repressing Pax7. The Journal of Cell Biology, 190(5), 867-879.

90. Dai, Y., et al. (2016). The role of microRNA-1 and microRNA-206 in the proliferation and differentiation of bovine skeletal muscle satellite cells. In Vitro Cellular and Developmental Biology - Animal, 52(1), 27-34.

91. Han, X., et al. (2015). Malat1 regulates serum response factor through miR-133 as a competing endogenous RNA in myogenesis. FASEB Journal, 29(7), 3054-3064.

92. Liu, B., et al. (2017). miR-221 modulates skeletal muscle satellite cells proliferation and differentiation. In Vitro Cellular and Developmental Biology - Animal, 54(2), 147-155.

93. Zhang, W. R., et al. (2017). miR-143 regulates proliferation and differentiation of bovine skeletal muscle satellite cells by targeting IGFBP5. In Vitro Cellular and Developmental Biology - Animal, 53(3), 265-271.

94. Dey, B. K., Gagan, J., \& Dutta, A. (2011). miR-206 and -486 induce myoblast differentiation by downregulating Pax7. Molecular and Cellular Biology, 31(1), 203-214.
95. Mehta, A., \& Baltimore, D. (2016). MicroRNAs as regulatory elements in immune system logic. Nature Reviews Immunology, 16(5), 279-294.

96. Copley, M. R., et al. (2013). The Lin28b-let-7-Hmga2 axis determines the higher self-renewal potential of fetal haematopoietic stem cells. Nature Cell Biology, 15(8), 916-925.

97. Zhou, Y., et al. (2015). Lin28b promotes fetal B lymphopoiesis through the transcription factor Arid3a. The Journal of Experimental Medicine, 212(4), 569-580.

98. Bissels, U., Bosio, A., \& Wagner, W. (2012). MicroRNAs are shaping the hematopoietic landscape. Haematologica, 97(2), 160-167.

99. Monticelli, S., et al. (2005). MicroRNA profiling of the murine hematopoietic system. Genome Biology, 6(8), R71.

100. Chen, C. Z., \& Lodish, H. F. (2005). MicroRNAs as regulators of mammalian hematopoiesis. Seminars in Immunology, 17(2), $155-165$.

101. Gangaraju, V. K., \& Lin, H. (2009). MicroRNAs: key regulators of stem cells. Nature Reviews Molecular Cell Biology, 10(2), $116-125$.

102. Sun, J., et al. (2014). Clonal dynamics of native haematopoiesis. Nature, 514(7522), 322-327.

103. Liu, L., et al. (2012). Homing and long-term engraftment of long- and short-term renewal hematopoietic stem cells. PLoS One, 7(2), e31300.

104. Crisan, M., \& Dzierzak, E. (2016). The many faces of hematopoietic stem cell heterogeneity. Development, 143(24), 4571-4581.

105. Wojtowicz, E. E., et al. (2016). Ectopic miR-125a expression induces long-term repopulating stem cell capacity in mouse and human hematopoietic progenitors. Cell Stem Cell, 19(3), 383-396.

106. Guo, S., et al. (2010). MicroRNA miR-125a controls hematopoietic stem cell number. Proceedings of the National Academy of Sciences of the United States of America, 107(32), 14229-14234.

107. Ooi, A. G., et al. (2010). MicroRNA-125b expands hematopoietic stem cells and enriches for the lymphoid-balanced and lymphoidbiased subsets. Proceedings of the National Academy of Sciences of the United States of America, 107(50), 21505-21510.

108. Han, Y. C., et al. (2010). microRNA-29a induces aberrant selfrenewal capacity in hematopoietic progenitors, biased myeloid development, and acute myeloid leukemia. The Journal of Experimental Medicine, 207(3), 475-489.

109. Lechman, E. R., et al. (2016). miR-126 regulates distinct selfrenewal outcomes in normal and malignant hematopoietic stem cells. Cancer Cell, 29(4), 602-606.

110. Lechman, E. R., et al. (2012). Attenuation of miR-126 activity expands HSC in vivo without exhaustion. Cell Stem Cell, 11(6), 799-811.

111. de Leeuw, D. C., et al. (2014). Attenuation of microRNA-126 expression that drives CD34 + 38- stem/progenitor cells in acute myeloid leukemia leads to tumor eradication. Cancer Research, 74(7), 2094-2105.

112. Martianez Canales, T., et al. (2017). Specific depletion of leukemic stem cells: can microRNAs make the difference? Cancers (Basel),. 9(7).

113. Testa, U., \& Pelosi, E. (2015). MicroRNAs expressed in hematopoietic stem/progenitor cells are deregulated in acute myeloid leukemias. Leukemia \& Lymphoma, 56(5), 1466-1474.

114. Krampera, M., et al. (2007). Mesenchymal stem cells: from biology to clinical use. Blood Transfusion, 5(3), 120-129.

115. Guo, L., Zhao, R. C., \& Wu, Y. (2011). The role of microRNAs in self-renewal and differentiation of mesenchymal stem cells. Experimental Hematology, 39(6), 608-616.

116. Li, J. P., et al. (2017). MiR-214 inhibits human mesenchymal stem cells differentiating into osteoblasts through targeting 
beta-catenin. European Review for Medical and Pharmacological Sciences, 21(21), 4777-4783.

117. Hodges, W. M., et al. (2017). Function of microRNAs in the osteogenic differentiation and therapeutic application of adiposederived stem cells (ASCs). International Journal of Molecular Sciences, 18(12).

118. Oskowitz, A. Z., et al. (2011). Drosha regulates hMSCs cell cycle progression through a miRNA independent mechanism. The International Journal of Biochemistry \& Cell Biology, 43(11), $1563-1572$.

119. Wang, Y., et al. (2012). miR-16 inhibits the proliferation and angiogenesis-regulating potential of mesenchymal stem cells in severe pre-eclampsia. FEBS Journal, 279(24), 4510-4524.

120. Lai, V. K., et al. (2012). MicroRNA-143 is a critical regulator of cell cycle activity in stem cells with co-overexpression of Akt and angiopoietin-1 via transcriptional regulation of Erk5/cyclin D1 signaling. Cell Cycle, 11(4), 767-777.

121. He, B., et al. (2016). Upregulated microRNA-143 inhibits cell proliferation in human nasopharyngeal carcinoma. Oncology Letters, 12(6), 5023-5028.

122. Peng, S., et al. (2016). MicroRNAs regulate signaling pathways in osteogenic differentiation of mesenchymal stem cells (Review). Molecular Medicine Reports, 14(1), 623-629.

123. Park, M. G., et al. (2014). MicroRNA-27 promotes the differentiation of odontoblastic cell by targeting APC and activating Wnt/ beta-catenin signaling. Gene, 538(2), 266-272.

124. You, L., et al. (2016). MiR-27a is essential for the shift from osteogenic differentiation to adipogenic differentiation of mesenchymal stem cells in postmenopausal osteoporosis. Cellular Physiology and Biochemistry, 39(1), 253-265.

125. Zhu, Y., et al. (2014). miR-27 inhibits adipocyte differentiation via suppressing CREB expression. Acta Biochim Biophys Sin (Shanghai), 46(7), 590-596.

126. Hamam, D., et al. (2015). microRNAs as regulators of adipogenic differentiation of mesenchymal stem cells. Stem Cells Dev, 24(4), 417-425.

127. Bendris, N., Lemmers, B., \& Blanchard, J. M. (2015). Cell cycle, cytoskeleton dynamics and beyond: the many functions of cyclins and CDK inhibitors. Cell Cycle, 14(12), 1786-1798.

128. Manning, A. L., \& Dyson, N. J. (2012). RB: mitotic implications of a tumour suppressor. Nature Reviews Cancer, 12(3), 220-226.

129. Thangavel, C., et al. (2017). RB loss promotes prostate cancer metastasis. Cancer Research, 77(4), 982-995.

130. Bai, X., et al. (2017). MicroRNA-142-5p induces cancer stem cell-like properties of cutaneous squamous cell carcinoma via inhibiting PTEN. Journal of Cellular Biochemistry, 119(2), 2179-2188

131. Bao, B., et al. (2012). Targeting CSC-related miRNAs for cancer therapy by natural agents. Current Drug Targets, 13(14), $1858-1868$

132. Lavon, I., et al. (2010). Gliomas display a microRNA expression profile reminiscent of neural precursor cells. Neuro-Oncology, 12(5), 422-433.

133. Vira, D., et al. (2012). Cancer stem cells, microRNAs, and therapeutic strategies including natural products. Cancer Metastasis Reviews, 31(3-4), 733-751.

134. Xia, W., et al. (2017). Smad inhibitor induces CSC differentiation for effective chemosensitization in cyclin D1- and TGFbeta/Smad-regulated liver cancer stem cell-like cells. Oncotarget, $8(24), 38811-38824$

135. Garg, M. (2015). Emerging role of microRNAs in cancer stem cells: Implications in cancer therapy. World Journal of Stem Cells, 7(8), 1078-1089.

136. Xu, Y. F., Hannafon, B. N., \& Ding, W. Q. (2017). microRNA regulation of human pancreatic cancer stem cells. Stem Cell Investigation, 4(5).
137. Peng, F., et al. (2017). H19/let-7/LIN28 reciprocal negative regulatory circuit promotes breast cancer stem cell maintenance. Cell Death \& Disease, 8(1), e2569.

138. Liu, X., et al. (2015). The regulation and function of miR-21FOXO3a-miR-34b/c signaling in breast cancer. International Journal of Molecular Sciences, 16(2), 3148-3162.

139. Li, B., et al. (2017). miR-221/222 promote cancer stem-like cell properties and tumor growth of breast cancer via targeting PTEN and sustained Akt/NF-kappaB/COX-2 activation. Chemico-Biological Interactions, 277, 33-42.

140. Liu, S., et al. (2012). MicroRNA93 regulates proliferation and differentiation of normal and malignant breast stem cells. PLoS Genetics, 8(6), e1002751.

141. Engkvist, M. E., et al. (2017). Analysis of the miR-34 family functions in breast cancer reveals annotation error of miR-34b. Science Reporter, 7(1), 9655.

142. Patel, N., et al. (2017). miR-15a/miR-16 down-regulates BMI1, impacting Ub-H2A mediated DNA repair and breast cancer cell sensitivity to doxorubicin. Science Reporter, 7(1), 4263.

143. Janaki Ramaiah, M., et al. (2017). Epigenetic regulation of miR-200 as the potential strategy for the therapy against triplenegative breast cancer. Gene, 641, 248-258.

144. Zhan, M. N., et al. (2017). MicroRNA-494 inhibits breast cancer progression by directly targeting PAK1. Cell Death \& Disease, 8(1), e2529.

145. Xiao, Z., et al. (2014). A small-molecule modulator of the tumor-suppressor miR34a inhibits the growth of hepatocellular carcinoma. Cancer Research, 74(21), 6236-6247.

146. Li, M., et al. (2017). miR-365 induces hepatocellular carcinoma cell apoptosis through targeting Bcl-2. Experimental and Therapeutic Medicine, 13(5), 2279-2285.

147. Kim, H. S., et al. (2015). MicroRNA-31 functions as a tumor suppressor by regulating cell cycle and epithelial-mesenchymal transition regulatory proteins in liver cancer. Oncotarget, 6(10), 8089-8102.

148. Ma, D. N., et al. (2016). MicroRNA-26a suppresses epithelialmesenchymal transition in human hepatocellular carcinoma by repressing enhancer of zeste homolog 2. Journal of Hematology \& Oncology, 9(1).

149. Sun, W., et al. (2016). MicroRNA-150 suppresses cell proliferation and metastasis in hepatocellular carcinoma by inhibiting the GAB1-ERK axis. Oncotarget, 7(10), 11595-11608.

150. Yu, C. C., et al. (2011). MicroRNA let-7a represses chemoresistance and tumourigenicity in head and neck cancer via stem-like properties ablation. Oral Oncol, 47(3), 202-210.

151. Wang, Y., et al. (2017). Lin28B facilitates the progression and metastasis of pancreatic ductal adenocarcinoma. Oncotarget, 8(36), 60414-60428.

152. Wang, P., et al. (2013). The serum miR-21 level serves as a predictor for the chemosensitivity of advanced pancreatic cancer, and miR-21 expression confers chemoresistance by targeting FasL. Molecular Oncology, 7(3), 334-345.

153. Karamitopoulou, E., et al. (2017). MicroRNA dysregulation in the tumor microenvironment influences the phenotype of pancreatic cancer. Modern Pathology, 30(8), 1116-1125.

154. Cioffi, M., et al. (2015). The miR-17-92 cluster counteracts quiescence and chemoresistance in a distinct subpopulation of pancreatic cancer stem cells. Gut, 64(12), 1936-1948.

155. Kang, M., et al. (2017). Concurrent treatment with simvastatin and NF-kappaB inhibitor in human castration-resistant prostate cancer cells exerts synergistic anti-cancer effects via control of the NF-kappaB/LIN28/let-7 miRNA signaling pathway. PLoS One, $12(9)$, $\mathrm{e} 0184644$.

156. Nabavi, N., et al. (2017). miR-100-5p inhibition induces apoptosis in dormant prostate cancer cells and prevents the 
emergence of castration-resistant prostate cancer. Science Reporter, 7(1), 4079.

157. Liu, C., et al. (2011). The microRNA miR-34a inhibits prostate cancer stem cells and metastasis by directly repressing CD44. Nature Medicine, 17(2), 211-215.

158. Galardi, S., et al. (2007). miR-221 and miR-222 expression affects the proliferation potential of human prostate carcinoma cell lines by targeting p27Kip1. The Journal of Biological Chemistry, 282(32), 23716-23724.

159. Silber, J., et al. (2013). Expression of miR-124 inhibits growth of medulloblastoma cells. Neuro-Oncology, 15(1), 83-90.

160. Tamim, S., et al. (2014). Genomic analyses reveal broad impact of miR-137 on genes associated with malignant transformation and neuronal differentiation in glioblastoma cells. PLoS One, 9(1), e85591.

161. Nie, X., Lin, Y., Yang, X., Guo, L., Que, S., Li, X., Ge, J., Wang, G., Xiong, W., Guo, P., \& Qiu, Y. (2015). IDH1R132H decreases the proliferation of U87 glioma cells through upregulation of microRNA-128a. Molecular Medicine Reports, 12(5), 6695-6701.

162. Geng, J., et al. (2012). Methylation mediated silencing of miR$23 \mathrm{~b}$ expression and its role in glioma stem cells. Neuroscience Letters, 528(2), 185-189.

163. Shi, L., et al. (2012). Functional differences of miR-125b on the invasion of primary glioblastoma CD133-negative cells and CD133-positive cells. Neuromolecular Medicine, 14(4), 303-316.

164. Rupaimoole, R., \& Slack, F. J. (2016). A role for miR-34 in colon cancer stem cell homeostasis. Stem Cell Investigation, 3, 42.

165. Ye, Y., et al. (2017). microRNA-605 promotes cell proliferation, migration and invasion in non-small cell lung cancer by directly targeting LATS2. Experimental and Therapeutic Medicine, 14(1), 867-873.

166. Yang, G., et al. (2015). MicroRNA let-7: regulation, single nucleotide polymorphism, and therapy in lung cancer. Journal of Cancer Research and Therapeutics, 11(Suppl 1), C1-6.

167. Okada, N., et al. (2014). A positive feedback between p53 and miR-34 miRNAs mediates tumor suppression. Genes \& Development, 28(5), 438-450.

168. Bandi, N., et al. (2009). miR-15a and miR-16 are implicated in cell cycle regulation in a $\mathrm{Rb}$-dependent manner and are frequently deleted or down-regulated in non-small cell lung cancer. Cancer Research, 69(13), 5553-5559.

169. O'Donnell, K. A., et al. (2005). c-Myc-regulated microRNAs modulate E2F1 expression. Nature, 435(7043), 839-843.

170. Sylvestre, Y., et al. (2007). An E2F/miR-20a autoregulatory feedback loop. The Journal of Biological Chemistry, 282(4), 2135-2143.

171. Pickering, M. T., Stadler, B. M., \& Kowalik, T. F. (2009). miR-17 and miR-20a temper an E2F1-induced G1 checkpoint to regulate cell cycle progression. Oncogene, 28(1), 140-145.

172. Yu, Z., et al. (2008). A cyclin D1/microRNA 17/20 regulatory feedback loop in control of breast cancer cell proliferation. The Journal of Cell Biology, 182(3), 509-517.

173. Babashah, S., \& Soleimani, M. (2011). The oncogenic and tumour suppressive roles of microRNAs in cancer and apoptosis. European Journal of Cancer, 47(8), 1127-1137.

174. $\mathrm{Mu}, \mathrm{P}$., et al. (2009). Genetic dissection of the miR-17 92 cluster of microRNAs in Myc-induced B-cell lymphomas. Genes \& Development, 23(24), 2806-2811.

175. Olive, V., Jiang, I., \& He, L. (2010). mir-17-92, a cluster of miRNAs in the midst of the cancer network. Int J Biochem Cell Biol, 42(8), 1348-1354.

176. Wong, P., et al. (2010). The miR-17-92 microRNA polycistron regulates MLL leukemia stem cell potential by modulating p21 expression. Cancer Research, 70(9), 3833-3842.
177. Balzeau, J., et al. (2017). The LIN28/let-7 Pathway in Cancer. Frontiers in Genetics, 8, 31.

178. Jakymiw, A., et al. (2010). Overexpression of dicer as a result of reduced let-7 microRNA levels contributes to increased cell proliferation of oral cancer cells. Genes, Chromosomes \& Cancer, 49(6), 549-559.

179. Li, X. X., et al. (2015). Reduced expression levels of let$7 \mathrm{c}$ in human breast cancer patients. Oncology Letters, 9(3), $1207-1212$.

180. Bueno, M. J., et al. (2011). Combinatorial effects of microRNAs to suppress the Myc oncogenic pathway. Blood, 117(23), 6255-6266.

181. Lewis, B. P., et al. (2003). Prediction of mammalian microRNA targets. Cell, 115(7), 787-798.

182. Bommer, G. T., et al. (2007). p53-mediated activation of miRNA34 candidate tumor-suppressor genes. Current Biology, 17(15), 1298-1307.

183. He, L., et al. (2007). A microRNA component of the p53 tumour suppressor network. Nature, 447(7148), 1130-1134.

184. Tazawa, H., et al. (2007). Tumor-suppressive miR-34a induces senescence-like growth arrest through modulation of the E2F pathway in human colon cancer cells. Proceedings of the National Academy of Sciences of the United States of America, 104(39), 15472-15477.

185. Sun, F., et al. (2008). Downregulation of CCND1 and CDK6 by miR-34a induces cell cycle arrest. FEBS Letters, 582(10), $1564-1568$

186. Calin, G. A., et al. (2008). MiR-15a and miR-16-1 cluster functions in human leukemia. Proceedings of the National Academy of Sciences of the United States of America, 105(13), 5166-5171.

187. Bottoni, A., et al. (2005). miR-15a and miR-16-1 down-regulation in pituitary adenomas. Journal of Cellular Physiology, 204(1), 280-285.

188. Klein, U., et al. (2010). The DLEU2/miR-15a/16 - 1 cluster controls B cell proliferation and its deletion leads to chronic lymphocytic leukemia. Cancer Cell, 17(1), 28-40.

189. Calin, G. A., et al. (2002). Frequent deletions and down-regulation of micro- RNA genes miR15 and miR16 at 13q14 in chronic lymphocytic leukemia. Proceedings of the National Academy of Sciences of the United States of America, 99(24), 15524-15529.

190. Cimmino, A., et al. (2005). miR-15 and miR-16 induce apoptosis by targeting BCL2. Proceedings of the National Academy of Sciences of the United States of America, 102(39), 13944-13949.

191. Linsley, P. S., et al. (2007). Transcripts targeted by the microRNA-16 family cooperatively regulate cell cycle progression. Molecular and Cellular Biology, 27(6), 2240-2252.

192. Asangani, I. A., et al. (2008). MicroRNA-21 (miR-21) posttranscriptionally downregulates tumor suppressor Pdcd4 and stimulates invasion, intravasation and metastasis in colorectal cancer. Oncogene, 27(15), 2128-2136.

193. Frankel, L. B., et al. (2008). Programmed cell death 4 (PDCD4) is an important functional target of the microRNA miR-21 in breast cancer cells. The Journal of Biological Chemistry, 283(2), $1026-1033$

194. Meng, F., et al. (2007). MicroRNA-21 regulates expression of the PTEN tumor suppressor gene in human hepatocellular cancer. Gastroenterology, 133(2), 647-658.

195. Chen, L., et al. (2011). Tumor-specific expression of microRNA26a suppresses human hepatocellular carcinoma growth via cyclin-dependent and -independent pathways. Molecular Therapy, 19(8), 1521-1528.

196. Zhu, Y., et al. (2012). MicroRNA-26a/b and their host genes cooperate to inhibit the G1/S transition by activating the $\mathrm{pRb}$ protein. Nucleic Acids Research, 40(10), 4615-4625. 